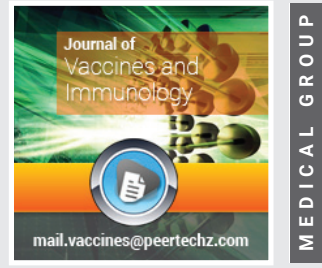

\title{
Considerations to accelerating and maximize the preclinical studies to a safe and effective
} COVID-19 vaccine

\author{
Reynaldo Oliva-Hernández* \\ Finlay Institute of Vaccine, Habana, Cuba
}

\section{Introduction}

The emergence of novel coronavirus-2019 (COVID-19) by Severe Acute Respiratory Syndrome Coronavirus 2 (SARSCoV-2) virus and its rapid spread across the world have triggered a global health emergency without preceding. From the first report of COVID-19 at Wuhan city of China in December 2019 until today there has been an outbreak of COVID-19 around the world, with 97, 831, 595 confirmed cases and 2, 120, 877 death cases $[1,2]$ and this number keeps growing.

Do not exist yet an effective drug is found for treating COVID-19 and a specific vaccine is the most promising hope. Therefore, intensive researches are urgently needed to speed up preclinical and clinical stages of the vaccines candidates, with the idea to provide some considerations to accelerating and maximizing the preclinical studies to a safe and effective COVID-19 vaccine, go this preclinical elements to share.

To achieve this aim, it is necessary to establish regulatory mechanisms to accelerate the development of vaccine candidates. The World Health Organization (WHO), the International Coalition of Drug Regulatory Authorities (ICMRA) and the Food and Drug administration FDA have made considerations or recommendations that allow accelerating the advancement of potential vaccines, if this one are based on vaccine platforms known platforms known [3,4]. Therefore, the previous preclinical and clinical safety features of other vaccines based on the same platform can be used to support accelerated advancement to early phases of clinical trials of new vaccine candidates based on known platforms.
Received: 18 January, 2021

Accepted: 23 January, 2021

Published: 25 January, 2021

*Corresponding author: Reynaldo Oliva-Hernández, Finlay Institute of Vaccine, Habana, Cuba, E-mail: roh@finlay.edu.cu, reyolivacuba@gmail.com ORCID: https://orcid.org/0000-0001-8198-9161 https://www.peertechz.com

\section{Check for updates}

\section{How would it be possible to accelerate the development of a vaccine from years to months?}

First has been the current context of the pandemic caused by COVID-19 that has allowed a redirection and a new approach to use both known drugs and non-specific vaccines against SARS-CoV-2 to try to stop this disease.

Second, the accumulated experience and the scientific information available have been the fundamental basis to arrive at a non-clinical evaluation strategy of a vaccine candidate against SARS-CoV-2; from which a risk analysis must be carried out, based on the concept that it would be a product based on a platform of known vaccines. Where the main risk would be associated with the duration of the nonclinical evaluation of the vaccine candidate, which could be significantly reduced by demonstrating that it would be based on a known platform. After these elements have been demonstrated, the risk associated with the non-clinical safety of the vaccine can be mitigated, showing that previous vaccines from the same development platform are safe and have passed the non-clinical and clinical toxicological evaluation phases.

The guidelines issued by the different international regulatory entities for conducting non-clinical evaluations or studies of drugs, biopharmaceuticals, vaccines and adjuvants (EMA, ICH, FDA, WHO), establish the need to comply with an extensive analytical battery non-clinical toxicological safety studies such as acute toxicity studies, single dose, local tolerance, repeated dose toxicity, reproduction studies, carcinogenesis, mutagenesis, teratogenesis, genotoxicity and immunotoxicology, among others [5-10]. Strict compliance 
with these tests implies years of studies and animal experimentation, which is why these same agencies have adjusted these regulations in the face of the global emergency caused by this coronavirus and the urgent need for vaccines to control the global epidemic.

Third, the design of the non-clinical toxicological evaluation of future vaccine candidates must be supported by the safety data accumulated by the other products of the platform, taking into account the known safety profiles of the components of the preceding vaccines, eg: the adjuvant (Aluminum), antigen-carrier proteins (Tetanus toxoid), or biomolecules with immunopotentiating properties such as the outer membrane vesicle of $N$. meningitides (OMV), which have been evaluated in preclinical toxicological studies and in clinical trials as components of commercial vaccines registered for use in humans $[11,12]$. In this sense, the general principle that biopharmaceuticals that are pharmacologically similar to a product for which there is extensive clinical experience, may require only a complementary non-clinical toxicological evaluation, is supported not only by the position papers of the WHO, ICMRA and FDA, due to the current epidemiological situation caused by COVID-19, but also in the 2001 ICH/S7A guide for preclinical evaluation of biopharmaceuticals [13].

\section{Optimize experiments to get more early safety informa- tion}

Finally, it is possible not only to accelerate the development of vaccine candidates against COVID-19, but it is also possible to maximize the evidence of efficacy and non-clinical safety from the first trial in animal models [14-16]. For this, the experimental design is key, where in most of the studies carried out in animals, not all the possible information is obtained, the historical tendency has been to answer one, two or three questions, in one or more animal models, eg.: immune response, dose levels, immunization schemes, protection, among others.

However, even knowing that the first experiments are based on formulations carried out at the laboratory level, under Good Laboratory Practice (GLP) and that these are not Good Manufacture Practice (GMP) prepared. In these "basic" studies can be assess in parallel, early elements of toxicity in immunogenicity schemes carried out in animals as safety criteria. The parameters to evaluate toxicity can be, the observation of clinical signs, the behavior of the body weight, the consumption of water, food, the body temperature, the local response to the administration of the product and macroscopic evaluation (necropsy). These parameters will make it possible to demonstrate the safety of the vaccine candidate with predictive value not only towards the toxicological studies themselves, but also towards the entire strategic projection of the product.

Summary, it is possible not only to accelerate non-clinical studies, maximize vaccine responses, but also reduce evaluation time from years to months.

\section{Acknowledgments}

I thank to anonymous reviewers for their helpful comments that improved the quality of this paper.

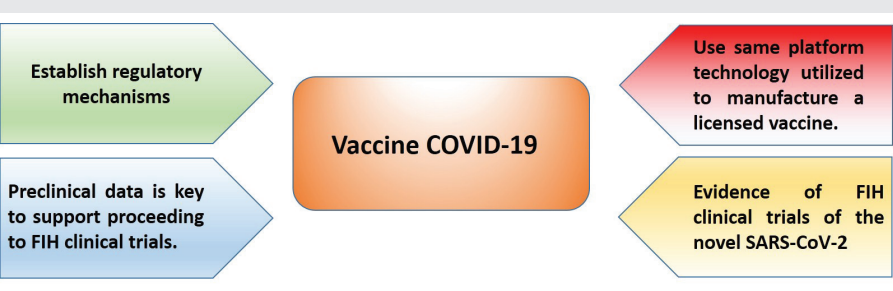

Key topics to support accelerate development timelines COVID-19 Vaccine.

\section{References}

1. Li Q, Guan X, Wu P, Wang X, Zhou L, et al. (2020) Early Transmission Dynamics in Wuhan, China, of Novel Coronavirus-Infected Pneumonia. N Engl J Med 382: 1199-1207. Link: https://bit.ly/3a1iev1

2. World Health Organization (WHO) (2021) COVID-19 Weekly Epidemiological Update. Link: https://bit.ly/3pe3zD6

3. World Health Organization (WHO) (2020) Update on WHO Solidarity Trial - Accelerating a safe and effective COVID-19 vaccine. Link: https://bit.ly/3pjvYYG

4. International Coalition of Medicines Regulatory Authorities (ICMRA) (2020) Global regulatory workshop on COVID-19 vaccine development. Link: https://bit.ly/3sW30A0

5. International Committee of Harmonization (ICH) (1992) Non-clinical local tolerance testing of medicinal products. CPMP/ICH/286/95, III (Addendum 2):137-148

6. International Committee of Harmonization (ICH) (1997) Non-clinical safety studies for the performance of human clinical trials for Pharmaceuticals. CPMP/ICH/286/95. Link: https://bit.ly/3ojku5P

7. International Committee of Harmonization (ICH) (1997) Requirements for Registration of Pharmaceuticals for human Use. Preclinical Safety evaluation of Biotechnology-Derived Pharmaceuticals. CPMP/ICH/302/95.

8. Food \& Drug Administration (FDA) (1997) S6 Preclinical Safety Evaluation of Biotechnology-Derived Pharmaceuticals. Link: https://bit.ly/39dQeFc .

9. World Health Organization (WHO) (2005) Guidelines on nonclinical evaluation of vaccine. Technical Report Series, No. 927. Link: https://bit.ly/3phpo4C

10. World Health Organization (WHO) (2013) Guidelines on the nonclinica evaluation of vaccine adjuvants and adjuvanted vaccines Annex 2. WHO Technical Report Series 1-56. Link: https://bit.ly/39bVtFE

11. Sierra VG (2020) Cuban meningococcal vaccine VA-MENGOC-BC $\AA$ : 30 Years of use and future potential. VacciMonitor 29: 31-43. Link: https://bit.ly/3iGHPOn

12. González N, Paredes B, Pérez S, Mirabal M, Rivero I, et al. (2015) Safety and Immunogenicity of Cuban Antipneumococcal Conjugate Vaccine PCV7-TT in Healthy Adults. MEDICC Review 17: 32-37. Link: https://bit.ly/2KIQMcQ

13. International Committee of Harmonization (2001) ICH/S7A. Harmonised Tripartite Guideline. Guidelines on safety Pharmacology studies for human drugs. Link: https://bit.ly/3qMBK57

14. Oliva R (2019) Preclinical toxicology considerations for vaccines. VacciMonitor 28: 48-51. Link: https://bit.ly/369xVz6

Citation: Oliva-Hernández R (2021) Considerations to accelerating and maximize the preclinical studies to a safe and effective COVID-19 vaccine. J Vaccines Immunol 7(1): 001-003. DOI: https://dx.doi.org/10.17352/jvi.000037 
15. European Medicines Agency (EMA) (2000) Note for guidance on repeated dose toxicity. London: CPMP/9. SWP/1042/99. Link: https://bit.ly/3sOntad
16. Food \& Drug Administration (FDA) (2020) Development and Licensure of Vaccines to Prevent COVID-19. Guidance for Industry. Link: https://bit.ly/3sW3gPu

Discover a bigger Impact and Visibility of your article publication with

\section{Peertechz Publications}

\section{Highlights}

* Signatory publisher of ORCID

* Signatory Publisher of DORA (San Francisco Declaration on Research Assessment)

- Articles archived in worlds' renowned service providers such as Portico, CNKI, AGRIS, TDNet, Base (Bielefeld University Library), CrossRef, Scilit, J-Gate etc.

* Journals indexed in ICMJE, SHERPA/ROMEO, Google Scholar etc.

* OAI-PMH (Open Archives Initiative Protocol for Metadata Harvesting)

* Dedicated Editorial Board for every journal

* Accurate and rapid peer-review process

* Increased citations of published articles through promotions

* Reduced timeline for article publication

Submit your articles and experience a new surge in publication services (https://www.peertechz.com/submission).

Peertechz journals wishes everlasting success in your every endeavours.

Copyright: (c) 2021 Oliva-Hernández R. This is an open-access article distributed under the terms of the Creative Commons Attribution License, which permits unrestricted use, distribution, and reproduction in any medium, provided the original author and source are credited.

Citation: Oliva-Hernández R (2021) Considerations to accelerating and maximize the preclinical studies to a safe and effective COVID-19 vaccine. J Vaccines Immunol 7(1): 001-003. DOI: https://dx.doi.org/10.17352/jvi.000037 